\title{
Uses of Social Media for Teledentistry by Millennial Dentist in Covid-19 era
}

\author{
Samsir Eka Putera ${ }^{1}$, Nurfauziah Syams Musamma ${ }^{2}$ \\ Master Student of Communication Science, Faculty of Social and Political Sciences, \\ Hasanuddin University, Makassar, Indonesia ${ }^{1,2}$ \\ \{Sputera93@gmail.com¹,nurfauzyah11.nf@gmail.com²
}

\begin{abstract}
Covid-19 has force us to change our habit in living our daily lives, one of them is on how young dentist uses their social media for teledentistry. Teledentistry itself is a dental innovation with telecommunication to help out of range patient. The focus of this research will be the millenial dentist working in private dental offices in Banjarbaru. This study aims to analyze the use of social media for teledentistry in covid-19 era. The method used in this research is descriptive qualitative. Data collection was carried out by means of observation, in-depth interviews, and documentation The results of this study indicate that social media used by millennial dentist for teledentistry has efficiently helped on reducing cost, time, and distance but it still has some minor problem on accuration since miscommunication still happened in the event of exchanging information.
\end{abstract}

Keywords: Social Media; Teledentistry; Information; Covid-19; Millennial

\section{Introduction}

With a spiraling entrance within the work of social media for health communication, it is practical to basically portray all inclusive distinctiveness of social media [1]. Social media can be characterized as online innovations that individuals use to share conclusions, encounters, and perspective with each other, as a better approach of communication that uses the internet to connect individuals from all over the world whether by utilizing computers or smartphones [2], [3]. However, the innovation of social media includes the collaboration and interaction of numerous clients, most of the interactions happen online through audio, visual, and textual content, it includes a sense of community, instead of people and has made it through all the hardships of distance, lack of information, lack of resources. In present day social orders, most suppliers of professional services compete for customers, and dental healthcare services are no exception.

Many social media tools are accessible for healthcare professionals, including social networking platforms, blogs, micro blogs, wiki, and media-sharing sites. These instruments can be utilized to move forward or upgrade professional networking and education, organizational promotion, patient care, patient education, and public health programs [4]. The use of more current communication innovations proceeds to exponentially increment, the healthcare professional will unavoidably grow out from the 'old' media (TV, radio, bulletins) 
and into the 'new' media (mobile phones, social media) [4]. However, the use of social media and social networking sites has ended up increasingly common by current generation individuals [5].

The prologue of social media has brought a transformation within the way individuals interact through the social web [4]. With the use of social media so frequent, it isn't surprising that clinics, specialist, and other healthcare professionals are utilizing social media to communicate with their patients. Dentistry has appeared an intrigued in utilizing social media to communicate and showcase to its patients. Coming into the world of social media may be a burdening assignment that should not be taken pointlessly. There are numerous moral and lawful issues associated with the use of social media in health-related areas [6]. The benefits of social media are at present seen within the field of healthcare and social media as a chief tactic in dental promoting. Social media promoting may be a cost-productive way to reach hundreds of planned moderns patients who explore for a practitioner's services and capability $[5]$.

One of the innovations in dental healthcare that has changed by the digitalization of dental services is the rise of telehealth or in dental healthcare goes by the name teledentistry. Teledentistry is a combination of telecommunications and dentistry. "Tele" is a Greek word meaning "distance" and "mederi" is a latin word meaning "to heal" [7]. Telemedicine (and by incorporation teledentistry) has been characterized in a number of ways. One definition is the hone of healthcare delivery, diagnosis, consultation, treatment, and education using interactive audio, video, or data communications" [8]. Teledentistry is a rapidly shaping subset of telehealth, a field that as of now has considerable impact on the healthcare industry. Cook in 1997 defined "teledentistry" as "the practice of using video-conferencing advances to diagnose and provide advice around treatment over a distance" [9].

Teledentistry is an exciting new area of dentistry that uses electronic health records, telecommunications technology, digital imaging, and the web to link healthcare supplier in rural or remote communities to upgrade communication, the exchange of health data, and access to care for underserved patients including socially impeded individuals, those who live in further or rural areas [10], [11]. Based on research done by Teerthankar Mahaveer Dental College and Research Centre in 2013 stated the benefit of teledentistry are reduced cost of service and improved quality of care, reduction in peer isolation and increased specialist support as well as education, general dentists will send multimedia patient records to dental specialists, often enabling the specialist to make a diagnosis and develop a treatment plan without having to see the patient in person, improvement in diagnostic services, improved integration of dentistry into the larger health care delivery system, improvement in communication with the Insurance industry with respect to requirements, improvement in communication with dental laboratories [7], [9], [11].

The most recent generation to enter the digital era are the millennial, who are people born between 1980 and 2000. They are called millennial because of their closeness to the new millennium and being raised in a more advanced age [12]. This era was impacted by the development of technology and a greater knowledge of computers [13]. Millennial appreciate utilizing technology. The millennial generation got to be dependent on technology at an earlier age than other generations. Much like learning a unused language, people who utilize technology at an earlier age ended up more proficient than individuals who learn afterward in their life [14]. It is thought that as more millennial start taking over the workplace, the more integrated innovation will be in work forms [12]. The use of social media by millennial has been growing increasingly large in the last decade. This growth goes together with how the technology has been evolving. 
The use of social media by millennial has been growing increasingly large in the last decade; this growth goes together with how the technology has been evolving. APJII (Association of Indonesian Internet Network Providers) data states that the survey results found that half of Indonesia's population uses the internet, namely 132.7 million people, while for adolescents or youth there are 23.8 million people. The data also shows that the number of social media users among teenagers is around 23.8 million people or $18 \%$ of Indonesia's population (APJII 2016 survey results). This proves that social media is very famous among the millennial who have the character of digital natives, where they have natural abilities that can quickly master the use of digital technology.

In the event of covid-19, World Health Organization has send out a guideline on that oral healthcare practices should follow. COVID-19 is transmitted primarily in three ways in oral health care settings: direct transmission through inhalation of droplets produced through coughing or sneezing, direct transmission by means of exposure of mucous membrane such as eye, nasal, or oral mucosa to infectious droplets, and indirect transmission through contaminated surfaces [15]. WHO advises that schedule of non-urgent oral health care-which ordinarily includes oral health checkups, dental cleanings, and preventive care to be postponed until there has been sufficient reduction in COVID-19 transmission rates from community transmission to cluster cases or concurring to official suggestions at national, sub-national or nearby level. The same applies to aesthetic dental treatments. In any case, urgent or emergency oral healthcare interventions that are crucial for protecting a person's oral functioning, managing extreme pain or securing quality of life ought to be provided.

Urgent or emergency oral healthcare may include interventions that address intense oral infections, swelling, systemic infection, critical or prolonged bleeding, severe pain not controllable with analgesia, oral health care interventions that are medically required as a preintervention to other pressing procedures; and dental/orofacial trauma [16]. If an oral healthcare professional is in doubt, referral to a specialized treatment facility must be ensuring. Timely administration of urgent or emergency oral healthcare interventions makes a difference patients avoid looking for treatment at hospital emergency departments, subsequently guaranteeing that they remain available to serve people looking for COVID-19 related care.

There are several precaution that need to be taken on opening oral healthcare practices in this pandemic situation, for example screen patients before their appointments either by virtual remote technology or telephone. Otherwise triage ought to be done on entry to the service or oral healthcare facility. The point is to ensure that as it were patients requiring urgent or emergency get treatment which they have no symptoms suggestive of COVID-19 disease or previous risk exposure. It is critical to note that not all individuals infected with COVID-19 exhibit symptoms, and cases without symptoms can transmit to others [17]. Whenever possible, create a remote evaluation of urgent or crisis oral healthcare patients by oral healthcare personnel based on the "3As" which is Advise, Analgesics, and Antibiotics [18]. if urgent or crisis is medically necessary for a patient who has, or is suspected of having COVID-19, the patient ought to be referred to specialized oral health care services with appropriate measures in place to separate possible COVID-19 cases from other patients. Where suitable urgent or emergency oral healthcare interventions may also be given on a domestic visit, this visitation will be conducted by a dedicated oral health care team applying strict infection prevention and control measures as locally prescribed.

During this pandemic situation the use of social media by the dentist who are born in millennial era have increased significantly, the reason is they are looking for alternative on reducing the infection of COVID-19 yet still able to give oral healthcare services to their 
patients. Lack of unified platform in teledentistry has made these millennial dentist chooses social media as a tool on improving their services, with a very high number of user in Indonesia made it very easy to communicate to their patient.

There are many researches on teledentistry around the world, but a research on how the media used in the process of teledentistry is apparently lacking. Most research done are focused on the technicality of how teledentistry work or how teledentistry are being accepted around the dentist, but the research on what platform teledentistry should be used or how does communication have a role in the process of teledentistry is little to be known.

\section{Research Methods}

\subsection{Type of Research}

This type of research is descriptive qualitative, namely a technique to describe and interpret the meaning of the data that has been collected by paying attention and record as many aspects of the situation under study at that time, to obtain a general and comprehensive picture of the actual situation (Kriyantono, 2007). According to Moleong (2010) using descriptive methods means that researchers analyze the collected data in the form of words, pictures and not numbers. Such data may come from interview scripts, field notes, photographs, video tapes, personal documents, notes or memos and other official documents.

\subsection{Subjects and Objects of Research}

\section{a) Research Subject}

The subjects of this study were the dentist who is working on a private dental service I Banjarbaru, Kalimantan Selatan. While the criteria for the informants in this study were:

1. The informant is a dentist working on a private dental services.

2. The informant was born between 1980-2000.

3. The informant understand how to operate social media.

4. The informants is using teledentistry in their services.

\section{b) Object of Research}

The object of this research is all forms of social media utilization by informants in teledentistry.

\subsection{Types of Data}

a. Primary data. The data that will be collected by researchers is based on the information obtained when meeting directly with informants. Primary data obtained from observations and interviews with research subjects.

b. Secondary data. Secondary data is obtained from literature studies, references, journals, articles, magazines, and internet and so on. This aims to be supporting data related to research. 


\subsection{Data Collection Techniques}

In accordance with the qualitative approach, the data collection techniques are used by researchers in this study include:

a. Interview. In this study, researchers used direct communication by asking open-ended questions, so that the information obtained was more complete and in-depth and related to the problem under study. This interview was conducted by means of a tape recorder. When the interview was carried out the researcher also recorded the main points, followed by a more complete and detailed recording after the interview was completed.

b. Observation. Some of the information obtained from the observation results is space (place), actor, activity, object, action, event or event, time, and feeling. The reason the researcher makes observations is to present a realistic picture of behavior or events, to answer questions, to help understand human behavior, and for evaluation, namely to measure certain aspects of doing feedback on these measurements.

c. Documentation. To complete the data needed in this study, the documentation method is used as a tool and a supporting tool. What is meant by the method of documentation is finding data about things or variables in the form of notes, transcripts, books, newspapers, magazines, inscriptions, meeting minutes, loggers, agendas and so on. Compared to other methods, this method is not that difficult, in the sense that if there is an error the data source is still unchanged. By the method of documentation, the observations are not living things but inanimate objects. So, the documentation method is a method used to obtain data in the form of writing materials.

\subsection{Data Validity}

The validity of the data will show that what the researcher observes is in accordance with what which is actually at the research location and the explanation of the problem description is in accordance with the actual situation. To analyze qualitative data, a technique called triangulation is used. Data Triangulation (Data Triangulation) where researchers use several data sources to collect the same or similar data. Investigator Triangulation (Researcher Triangulation) the validity of the research results, either data or conclusions regarding certain parts or the whole can be tested by several researchers. Methodological Triangulation (Triangulation Methodology) researchers collect similar data but using different data collection techniques or methods.

Theoritical Triangulation (Triangulation Theory) researchers use the perspective of more than one theory in discussing the problems being studied. From some of these theoretical perspectives, a more complete view will be obtained, not only one-sided, so that more complete and comprehensive conclusions can be analyzed and drawn. The triangulation used in this study was data triangulation and method triangulation. Where data triangulation is used for similar data collection using a variety of different data sources. While the triangulation method is used to compare the data from the interview results, namely comparing what is in the document with the results of the observations and comparing the results of the interview with the contents of the related documents. 


\subsection{Data Analysis}

The analytical process in qualitative research is often the most difficult part. There are three main components that must be fully understood by researchers, namely (1) data reduction, (2) data display, (3) decision making or verification.

a. Data Reduction. Data reduction is the first component in the analysis which is a process of selecting, focusing, simplifying, and abstraction of available data. Data reduction is part of the analysis process which emphasizes, shortens, focuses, removes unnecessary things, and organizes data in such a way that the conclusions of the research can be carried out.

b. Data Presentation. As the second analysis, the data presentation is a series of information, a description in the form of a narrative arranged logically and systematically which refers to the formulation of the problem which has been formulated as a research question. The data presentation is a description of the detailed conditions to tell and answer each problem in the study. This is intended to facilitate understanding of the description of the phenomena that exist in the object of research.

c. Verification / Conclusion Withdrawal. The data obtained since the beginning of the study is actually a conclusion. This conclusion is unclear at first and is still temporary in nature, then it rises to the stage of a solid conclusion, namely a statement that already has a strong foundation because it has gone through the data analysis process.

\subsection{Research Procedure}

The research procedure is the stages taken in a research that starts from the beginning to the end of the study. The procedures carried out in this study are as follows:

a. Research Preparation Stage. At this stage, various activities are carried out before the researcher goes into the field, starting from submitting titles, making research proposals and arranging permits to smooth the course of the research.

b. Data Collection Stage. In carrying out data collection, researchers used three techniques, namely: interviews, observation, and documentation. These three techniques are used to complement other data so that the data collected is truly valid.

c. Data Analysis Phase. This stage is used to find out whether the data collected is as expected.

d. Final Data Analysis Stage. The final data analysis was performed after the initial data were analyzed. The data analyzed in this stage are all data obtained in data collection which is supporting data in achieving the research objectives. If the data is deemed insufficient to support the aims and objectives of the research, the researcher can collect the data again and carry out the initial analysis.

e. Conclusion Withdrawal Stage. Conclusions are drawn based on research objectives that are supported by valid data, so that the research results obtained can be justified.

f. Report Writing and Reproduction Stage. This stage is the final stage of research which includes all activities related to research and the results achieved, written and reported to interested parties in the form of reports in accordance with predetermined conditions.

\section{Results and Discussion}

Based on the results of research on the use of social media by millennial dentist in the city of Banjarbaru includes the following: 
a. The type of social media used by the millennial dentist in the city of Banjarbaru. The use of social media by the owner or manager is very diverse; the most used types of social media are Whatsapp, Facebook, and Instagram. This was chosen because this type of social media is very easy to operate and very familiar to distribution consumers.

b. Social media use as a tool for teledentistry in the city of Banjarbaru. The use of social media as a teledentistry medium by millennial dentist in the city of Banjarbaru is very big, this is because the use of social media for teledentistry does not requires almost any amount of money at all and for millennial dentist it allow them to open practices and have oral healthcare services in pandemic situation. Only $13 \%$ of the millennial dentist do not use social, while the remaining $87 \%$ uses social media to help them reach their patient.

c. The function of using the social media as a tool of information technology in teledentistry processes. Most of the millennial dentist state that social media is very supportive of the teledentistry process, especially with reducing cost on patient, less time on waiting room, helping them screening patient, and giving home services. Most millennial dentist state that meeting patient face to face in their practices is still a huge risk with infection with COVID-19 and with utilizing social media they can prevent infection between patient to patient or patient to dentist.

d. As a means of communication between millennial dentist and patients. With the existence of social media, it can bring the millennial dentist closer to patients, but there are still a few miscommunications happen during exchanging information in the process of teledentistry this is reflected in the communication that exists between the dentist and patients on Whatsapp, Facebook, and Instagram. When the dentist and the patients is exchanging information, some information may be loss or not be stated clearly across the social media. The reason could be from language barrier, uses of medical word may confuse the patients which sometime make the teledentistry process take more time to process.

\section{Conclusions and Suggestions}

Most of millennial dentist in the city of Banjarbaru have utilize social media as platform in teledentistry. From the results of the research conducted, here are some suggestions that researchers can convey.

a. The millennial dentist to further improve the use of existing social media.

b. Word chosen during teledentistry in social media to be more common in order to make it easier for patients to understand the information given and to lessen the miscommunication between them.

\section{References}

[1] Moorhead SA, Hazlett DE, Harrison L, Carroll JK, Irwin A, et al: A new dimension of health care: systematic review of the uses, benefits, and limitations of social media for health communication. J Med Internet Res 15: e85. (2013)

[2] Boyd DM, Ellison NB: Social network sites: Definition, history, and scholarship. J Comput-Mediated Commun 13: 210-30. (2007)

[3] Stephen AT, Galak J: The effects of traditional and social earned media on sales: A study of a microlending marketplace. J Marketing Res 49: 624-39. (2012) 
[4] Nelson KL, Shroff B, Best AM, Lindauer SJ: Orthodontic marketing through social media networks: The patient and practitioner's perspective. Angle Orthod 85: 1035-41. (2015)

[5] DuBose C: The social media revolution. Radiologic technology 83: 112-9. (2011)

[6] Henry RK, Molnar A, Henry JC: A survey of US dental practices' use of social media. J Contemp Dent Pract 13: 137-41. (2012)

[7] Sanjeev M, Garg SK. Teledentistry a new trend in oral health, Int J Clin Cases lnvest; 2:49-53. (2011)

[8] Ata SO, Ozkan S, Information Technology in Oral Health Care: Attitudes of Dental Professionals on the Use of Teledentistry in Turkey. Eur Mediterranean Conf Information System:1-8. (2009)

[9] Bhambal A, Saxena S, Balsaraf SV, Teledentistry: potentials unexplored. J Int Oral Health; 2:1-6. (2010)

[10] Using Teledentistry to Improve Access to Dental Care for the Underserved. Dent Clin North Am 2009; 53:537-48. (2009)

[11] Torres-Pereira CC, Morosini Ide A, Possebon RS, Giovanini AF, Bortoluzzi MC, Leão JC, Piazzetta CM. Teledentistry: Distant Diagnosis of Oral Disease Using E-Mails. Telemed J E Health.;19(2):117-21. (2013)

[12] Kaifi, B. A., Nafei, W. A., Khanfar, N. M., \& Kaifi, M. M.: A multi-generational workforce: managing and understanding millennials. International Journal of Business \& Management, 7(24), 88-93. (2012)

[13] Andert, D.: Alternating leadership as a proactive organizational intervention: addressing the needs of the baby boomers, generation xers and millennials. Journal Of Leadership, Accountability \& Ethics, 8(4), 67-83. (2011)

[14] Deal, J., Altman, D., \& Rogelberg, S.: Millennials at work: what we know and what we need to do (if anything). Journal of Business \& Psychology, 25(2), 191-199. (2010)

[15] Peng X, Xu X, Li Y, Cheng L, Zhou X, Ren B. Transmission routes of 2019-nCoV and controls in dental practice. Int J Oral Sci.;12(1):9. (2020)

[16] American Dental Association. What Constitutes a Dental Emergency? https://success.ada.org/ /media/CPS/Files/Open\%20Files/ADA_COVID19_Dental_E mergency_DDS.pdf. Published 2020. Accessed 18 May, 2020.

[17] World Health Organization. Transmission of SARSCoV-2: implications for infection prevention precautions: scientific brief, 09 July 2020. https://apps.who.int/iris/handle/10665/333114. Published 2020. Accessed 23 July, 2020.

[18] Scottish Dental Clinical Effectiveness Programme. Management of Acute Dental Problems During COVID19 Pandemic. http://www.sdcep.org.uk/wpcontent/uploads/2020/03/SDCEP-MADP-COVID-19guide-300320.pdf. Published 2020. Accessed 23 July, 2020. 